\section{JURNAL EKONOMI EFEKTIF}

ISSN : $2622-8882$, E-ISSN : 2622-9935

Jurnal Ekonomi Efektif, Vol. 3, No. 3, April 2021

@Prodi Manajemen Fakultas Ekonomi Universitas

Pamulang

\title{
PENGARUH LINGKUNGAN KERJA DAN KEPEMIMPINAN TERHADAP KINERJA KARYAWAN PADA PT. UNIFORM INDONESIA DI JAKARTA
}

\author{
Devi Fitria Wilandari \\ Universitas Pamulang, Tangerang Selatan, Banten, Indonesia \\ dosen02529@unpam.ac.id
}

Manuskrip: Mar-2021 Ditinjau: Mar-2021; Diterima: Mar-2021; Online: Apr-2021; Diterbitkan: Apr-2021

\begin{abstract}
ABSTRAK
Penelitian ini bertujuan untuk mengetahui pengaruh lingkungan kerja dan kepemimpinan terhadap kinerja karyawan pada PT. Uniform Indonesia di Jakarta. Metode yang digunakan adalah explanatory research dengan teknik analisis menggunakan analisis statistik dengan pengujian regresi, korelasi, determinasi dan uji hipotesis. Hasil penelitian ini lingkungan kerja berpengaruh signifikan terhadap kinerja karyawan sebesar 43,6\%, uji hipotesis diperoleh $\mathrm{t}$ hitung $>\mathrm{t}$ tabel atau $(8,276>2,008)$. Kepemimpinan berpengaruh signifikan terhadap kinerja karyawan sebesar 46,8\%, uji hipotesis diperoleh $\mathrm{t}$ hitung $>\mathrm{t}$ tabel atau $(6,109>2,008)$. Lingkungan kerja dan kepemimpinan secara simultan berpengaruh signifikan terhadap kinerja karyawan dengan persamaan regresi $\mathrm{Y}=10,013+0,285 \mathrm{X} 1+$ $0,325 \mathrm{X} 2$ dan kontribusi pengaruh sebesar 56,0\%, uji hipotesis diperoleh $\mathrm{F}$ hitung $>\mathrm{F}$ tabel atau $(31,861>2,790)$.
\end{abstract}

Kata Kunci: Lingkungan Kerja, Kepemimpinan, Kinerja Karyawan.

\begin{abstract}
This study aims to determine the effect of work environment and leadership on employee performance at PT. Indonesian Uniform in Jakarta. The method used is explanatory research with analysis techniques using statistical analysis with regression testing, correlation, determination and hypothesis testing. The results of this study, the work environment has a significant effect on employee performance by 43.6\%, hypothesis testing is obtained t count> t table or (8.276> 2.008). Leadership has a significant effect on employee performance by $46.8 \%$, hypothesis testing is obtained t count $>$ t table or $(6.109>2.008)$. Work environment and leadership simultaneously have a significant effect on employee performance with the regression equation $Y=10.013+0.285 X 1+0.325 X 2$ and the contribution of influence is $56.0 \%$, hypothesis testing is obtained $F$ count $>F$ table or $(31.861>2.790)$.
\end{abstract}

Keywords: Work Environment, Leadership, Employee Performance. 


\section{PENDAHULUAN}

\section{A. Latar Belakang Masalah}

Manajemen sumber daya manusia pada dasarnya merupakan langkah- langkah perencanaan, penarikan, seleksi, pengembangan pemeliharaan dan penggunaan sumber daya manusia untuk mencapai tujuan baik individu maupun organisasional. Pada umumnya karyawan cenderung lebih senang dengan adanya kondisi lingkungan kerja yang baik dan nyaman, sehingga efesiensi kerja suatu organisasi atau instansi dapat tercapai dengan baik dan optimal. Jadi di dalam organisasi tanpa peran manusia tidak akan berjalan dengan secara lancar. Untuk itu diperlukan adanya suatu manajemen yang baik untuk mengatur orang tersebut secara efektif dan efisien, agar tujuan yang telah ditetapkan oleh perusahaan dapat terwujud. Oleh karna itu suatu perusahaan dapat maju atau hancur akibat dari kualitas dan tingkah laku manusia yang ada di dalam perusahaan tersebut.

Menurut Sedarmayanti (2007:21) mengatakan bahwa lingkungan kerja adalah keseluruhan alat perkakas dan bahan yang dihadapi, lingkungan sekitarnya dimana seseorang bekerja, metode kerjanya, serta pengaturan sistem kerja yang baik sebagai perseorangan maupun sebagai kelompok.

Seiring dengan cepatnya perubahan lingkungan eksternal dan teknologi informasi dan komunikasi dewasa ini maka dalam upaya menciptakan lingkungan yang baik, maka peran pemimpin sangatlah penting terutama dalam memiliki struktur organisasi dan gaya manajemen yang akan diterapkan. Pemilihan ini harus benar-benar melalui analisis lingkungan yang sangat cermat. Perlu dipilih gaya manajemen yang sesuai dengan situasi dan kondisi lingkungan kerja. Tujuannya adalah untuk mewujudkan perusahaan dengan kinerja tinggi. Kinerja dalam menjalankan fungsinya tidak berdiri sendiri, tetapi berhubungan dengan kepuasan kerja dan tingkat imbalan, dipengaruhi oleh ketrampilan, kemampuan dan sifat-sifat individu.

Menurut Miftah Thoha (2010:49) mengemukakan bahwa: "Kepemimpinan merupakan norma prilaku yang digunakan oleh seseorang pada saat orang tersebut mencoba mempengaruhi prilaku orang lain atau bawahan”. Sedangkan menurut Sedarmayanti (2011:260), Kinerja Karyawan adalah hasil kerja seorang pekerja, sebuah proses manajemen atau suatu organisasi secara keseluruhan, dimana hasil kerja tersebut harus dapat ditunjukkan buktinya secara konkrit dan dapat diukur dengan standar yang telah ditentukan.

Kinerja karyawan dapat dipengaruhi oleh lingkungan kerja, dimana apabila lingkungan kerja perusahaan baik maka kinerja karyawannya pun akan meningkat. Sedangkan lingkungan kerja yang terdapat di perusahaan masih terdapat masalah terutama dalam hal suara bising yang masih mengganggu karyawa dalam melakukan aktivitas kerjanya dan juga masih terbatasnya ruang gerak karyawan yang tersedia sehingga karyawan tidak leluasa dalam bekerja. Hal ini membuat perusahaan harus dapat meningkatkan lagi lingkungan kerjanya agar kinerja para karyawannya tidak terganggu dan supaya dapat ditingkatkan.

Selain lingkungan kerja, kinerja karyawan juga dapat dipengaruhi oleh kepemimpinan. Kepemimpinan yang baik akan dapat meningkatkan kualitas dan kinerja para karyawannya. Kepemimpinan yang terdapat pada perusahaan masih terdapat kepemimpinan yang kurang demokratis sehingga para karyawan masih merasa kurang didengarkan pendapatnya oleh pimpinannya. Selain itu pimpinan perusahaan juga masih bersifat otoriter yang membuat karyawan harus selalu mengikuti kemauan pimpinannya tanpa diberikan keleluasaan dalam bekerja.

Berdasarkan lingkungan kerja dan kepemimpinan tersebut membuat kinerja 
karyawan menurun pada perusahaan. Masalah yang timbul akibat permasalahan tersebut adalah menurunnya kualitas kerja para karyawan yang diakibatkan lingkungan kerja yang masih kurang kondusif karena suara bising. Karyawan dalam perusahaan juga masih memiliki tanggung jawab yang kurang terhadap tugasnya karena sikap pimpinan mereka yang masih bersifat otoriter yang membuat karyawan merasa tertekan dan kurangnya rasa segan serta menghormati pimpinannya sehingga mengabaikan tugas dan pekerjaannya.

PT. Uniform Indonesia merupakan perusahaan yang memproduksi alat cetak ofsset, didirikan pada pertengahan era 80an pada masa dunia grafika Indonesia mengalami peralihan dari teknik cepat Letterpress ke teknik cetak Offset. Hal ini menyebabkan adanya kebutuhan akan rol karet yang lebih handal dan berkualitas. Dengan makin bertambahnya permintaan, maka pada kurun dasawarsa terakhir kami telah melakukan diversifikasi produk dengan melayani sektor di luar industri grafika. Produk-produk Uniform yang lebih beraneka ragam dapat ditemui pada hampir semua industri modern. Dengan pengalaman serta dedikasi profesionalisme, kami yakin untuk tetap menjadi pelaku utama dalam industri rol karet, tidak hanya di Indonesia melainkan juga di manca negara.

Berdasarkan uraian diatas, maka peneliti tertarik untuk melakukan penelitian serta pembahasan masalah mengenai: "Pengaruh Lingkungan Kerja dan Kepemimpinan Terhadap Kinerja Karyawan pada PT. Uniform Indonesia di Jakarta”.

\section{B. Rumusan Masalah}

1. Adakah pengaruh antara lingkungan kerja terhadap kinerja karyawan pada PT. Uniform Indonesia di Jakarta?

2. Adakah pengaruh antara kepemimpinan terhadap kinerja karyawan pada PT. Uniform Indonesia di Jakarta?

3. Adakah pengaruh secara simultan antara lingkungan kerja dan kepemimpinan terhadap kinerja karyawan pada PT. Uniform Indonesia di Jakarta?

\section{Tujuan Penelitian}

1. Untuk mengetahui pengaruh antara lingkungan kerja terhadap kinerja karyawan pada PT. Uniform Indonesia di Jakarta.

2. Untuk mengetahui pengaruh antara kepemimpinan terhadap kinerja karyawan pada PT. Uniform Indonesia di Jakarta.

3. Untuk mengetahui pengaruh secara simultan antara lingkungan kerja dan kepemimpinan terhadap kinerja karyawan pada PT. Uniform Indonesia di Jakarta.

\section{METODE PENELITIAN}

\section{Populasi} Jakarta

Populasi dalam penelitian ini berjumlah 53 responden PT. Uniform Indonesia di

\section{Sampel}

Sampel dalam penelitian ini berjumlah 53 responden.

\section{Jenis Penelitian}

Jenis penelitian yang dipakai adalah asosiatif, dimana tujuannya adalah untuk mengetahui pengaruh antara variabel bebas terhadap variabel terikat baik parsial maupun simultan

\section{Metode Analisis Data}

Dalam menganalisis data digunakan uji instrumen, uji asumsi klasik, regresi, 
koefisien determinasi dan uji hipotesis.

\section{HASIL PENELITIAN DAN PEMBAHASAN}

\section{Analisis Deskriptif}

Pada pengujian ini digunakan untuk mengetahui skor minimum dan maksimum, mean score dan standar deviasi dari masing-masing variabel. Adapun hasilnya sebagai berikut:

Tabel 1. Hasil Analisis Descriptive Statistics

\section{Descriptive Statistics}

\begin{tabular}{|l|r|r|r|r|r} 
& N & \multicolumn{1}{c|}{ Minimum } & Maximum & Mean & \multicolumn{1}{c}{ Std. Deviation } \\
\hline Lingkungan kerja (X1) & 53 & 32 & 48 & 38.12 & 4.019 \\
\hline Kepemimpinan (X2) & 53 & 30 & 46 & 38.32 & 3.664 \\
\hline Kinerja Karyawan (Y) & 53 & 32 & 47 & 39.16 & 3.499 \\
\hline Valid N (listwise) & 53 & & & & \\
\hline
\end{tabular}

Lingkungan kerja diperoleh varians minimum sebesar 32 dan varians maximum 48 dengan mean score sebesar 3,81 dengan standar deviasi 4,019.

Kepemimpinan diperoleh varians minimum sebesar 30 dan varians maximum 46 dengan mean score sebesar 3,83 dengan standar deviasi 3,664.

Kinerja karyawan diperoleh varians minimum sebesar 32 dan varians maximum 47 dengan mean score sebesar 3,91 dengan standar deviasi 3,499.

\section{Analisis Verifikatif.}

Pada analisis ini dimaksudkan untuk mengetahui pengaruh variabel independen terhadap variabel dependen. Adapun hasil pengujian sebagai berikut:

\section{a. Analisis Regresi Linier Berganda}

Uji regresi ini dimaksudkan untuk mengetahui perubahan variabel dependen jika variabel independen mengalami perubahan. Adapun hasil pengujiannya sebagai berikut:

Tabel 2. Hasil Pengujian Regresi Linier Berganda

\begin{tabular}{|c|c|c|c|c|c|c|}
\hline \multirow{3}{*}{\multicolumn{2}{|c|}{ Model }} & \multicolumn{3}{|c|}{ Coefficients $^{a}$} & \multirow[b]{3}{*}{$t$} & \multirow[b]{3}{*}{ Sig. } \\
\hline & & \multicolumn{2}{|c|}{$\begin{array}{l}\text { Unstandardized } \\
\text { Coefficients }\end{array}$} & \multirow{2}{*}{$\begin{array}{c}\text { Standardized } \\
\text { Coefficients } \\
\text { Beta }\end{array}$} & & \\
\hline & & $\mathrm{B}$ & Std. Error & & & \\
\hline & (Constant) & 10.013 & 4.626 & & 2.165 & .035 \\
\hline & Lingkungan kerja (X1) & .285 & .072 & .438 & 3.958 & .000 \\
\hline & Kepemimpinan (X2) & .352 & .094 & .417 & 3.763 & .000 \\
\hline
\end{tabular}

a. Dependent Variable: Kinerja Karyawan (Y)

Berdasarkan hasil pengujian pada tabel di atas, diperoleh persamaan regresi $\mathrm{Y}$ $=10,013+0,285 \mathrm{X} 1+0,325 \mathrm{X} 2$. Dari persamaan tersebut dijelaskan sebagai berikut:

1) Konstanta sebesar 10,013 diartikan jika lingkungan kerja dan kepemimpinan tidak ada, maka telah terdapat nilai kinerja karyawan sebesar 10,013 point.

2) Koefisien regresi lingkungan kerja sebesar 0,285 , angka ini positif artinya setiap ada peningkatan lingkungan kerja sebesar 0,285 maka kinerja karyawan juga akan mengalami peningkatan sebesar 0,285 point.

3) Koefisien regresi kepemimpinan sebesar 0,325 , angka ini positif artinya setiap ada peningkatan kepemimpinan sebesar 0,325 maka kinerja karyawan juga akan mengalami peningkatan sebesar 0,325 point.

\section{b. Analisis Koefisien Korelasi}

Analisis koefisien korelasi dimaksudkan untuk mengetahui tingkt kekuatan hubungan dari variabel independen terhadap variabel dependen baik secara parsial 
maupun simultan. Adapun hasil pengujian sebagai berikut:

Tabel 3. Hasil Pengujian Koefisien Korelasi Lingkungan kerja Terhadap Kinerja Karyawan.

\begin{tabular}{llrrr} 
& \multicolumn{2}{c}{ Correlations $^{b}$} & $\begin{array}{c}\text { Lingkungan } \\
\text { kerja (X1) }\end{array}$ & $\begin{array}{r}\text { Kinerja Karyawan } \\
(Y)\end{array}$ \\
\hline Lingkungan kerja (X1) & Pearson Correlation & 1 & $.660^{* *}$ \\
\cline { 2 - 4 } & Sig. (2-tailed) & .000 \\
\hline Kinerja Karyawan (Y) & Pearson Correlation & $.660^{* *}$ & 1 \\
\cline { 2 - 4 } & Sig. (2-tailed) & .000 & \\
\hline
\end{tabular}

Berdasarkan hasil pengujian diperoleh nilai korelasi sebesar 0,660 artinya lingkungan kerja memiliki hubungan yang kuat terhadap kinerja karyawan.

Tabel 4. Hasil Pengujian Koefisien Korelasi Kepemimpinan Terhadap Kinerja

\begin{tabular}{|c|c|c|c|}
\hline & $\begin{array}{r}\text { Karya } \\
\text { Correlat }\end{array}$ & $\begin{array}{l}\mathbf{S}^{\mathbf{b}} \\
\text { Kepemimpinan }\end{array}$ & Kinerja Karyawan $(\mathrm{Y})$ \\
\hline Kepemimpinan (X2) & $\begin{array}{l}\text { Pearson Correlation } \\
\text { Sig. (2-tailed) }\end{array}$ & 1 & $\begin{array}{r}.650^{*} \\
.000\end{array}$ \\
\hline Kinerja Karyawan (Y) & $\begin{array}{l}\text { Pearson Correlation } \\
\text { Sig. (2-tailed) }\end{array}$ & $\begin{array}{r}.650^{* *} \\
.000\end{array}$ & 1 \\
\hline
\end{tabular}

Berdasarkan hasil pengujian diperoleh nilai korelasi sebesar 0,650 artinya kepemimpinan memiliki hubungan yang kuat terhadap kinerja karyawan.

Tabel 5. Hasil Pengujian Koefisien Korelasi Lingkungan kerja dan Kepemimpinan secara simultan Terhadap Kinerja Karyawan.

\section{Model Summary}

\begin{tabular}{lrr|rr|r} 
& & \multicolumn{2}{|c|}{$\begin{array}{c}\text { Adjusted R } \\
\text { Model }\end{array}$} & \multicolumn{2}{c}{$\begin{array}{c}\text { Std. Error of the } \\
\text { Estimate }\end{array}$} \\
\hline 1 & $.749^{\mathrm{a}}$ & R Square & .560 & .543 & 3.048 \\
\hline
\end{tabular}

a. Predictors: (Constant), Kepemimpinan (X2), Lingkungan kerja (X1)

Berdasarkan hasil pengujian diperoleh nilai korelasi sebesar 0,749 artinya lingkungan kerja dan kepemimpinan secara simultan memiliki hubungan yang kuat terhadap kinerja karyawan.

\section{c. Analisis Koefisien Determinasi}

Analisis koefisien determinasi dimaksudkan untuk mengetahui besarnya persentase pengaruh dari variabel independen terhadap variabel dependen baik secara parsial maupun simultan. Adapun hasil pengujian sebagai berikut:

Tabel 6. Hasil Pengujian Koefisien Determinasi Lingkungan kerja Terhadap Kinerja Karyawan.

\section{Model Summary}

\begin{tabular}{|c|c|c|c|c|}
\hline \multicolumn{5}{|c|}{ ary } \\
\hline Model & $\mathrm{R}$ & R Square & $\begin{array}{l}\text { Adjusted R } \\
\text { Square }\end{array}$ & $\begin{array}{l}\text { Std. Error of the } \\
\text { Estimate }\end{array}$ \\
\hline 1 & $.660^{\mathrm{a}}$ & .436 & .425 & 3.419 \\
\hline
\end{tabular}

Berdasarkan hasil pengujian diperoleh nilai determinasi sebesar 0,436 artinya lingkungan kerja memiliki kontribusi pengaruh sebesar 43,6\% terhadap kinerja karyawan. 
Tabel 7. Hasil Pengujian Koefisien Determinasi Kepemimpinan Terhadap Kinerja Karyawan.

\section{Model Summary}

\begin{tabular}{|c|c|c|c|c|}
\hline Model & $\mathrm{R}$ & R Square & $\begin{array}{l}\text { Adjusted R } \\
\text { Square }\end{array}$ & $\begin{array}{l}\text { Std. Error of the } \\
\text { Estimate }\end{array}$ \\
\hline 1 & $.650^{a}$ & .423 & .411 & 3.459 \\
\hline
\end{tabular}

Berdasarkan hasil pengujian diperoleh nilai determinasi sebesar 0,468 artinya kepemimpinan memiliki kontribusi pengaruh sebesar 46,8\% terhadap kinerja karyawan.

Tabel 8. Hasil Pengujian Koefisien Determinasi Lingkungan kerja dan Kepemimpinan Terhadap Kinerja Karyawan.

\section{Model Summary}

\begin{tabular}{|c|c|c|c|c|}
\hline Model & $\mathrm{R}$ & R Square & $\begin{array}{l}\text { Adjusted R } \\
\text { Square }\end{array}$ & $\begin{array}{l}\text { Std. Error of the } \\
\text { Estimate }\end{array}$ \\
\hline 1 & $.749^{a}$ & .560 & .543 & 3.048 \\
\hline
\end{tabular}

Berdasarkan hasil pengujian diperoleh nilai determinasi sebesar 0,560 artinya lingkungan kerja dan kepemimpinan secara simultan memiliki kontribusi pengaruh sebesar 56,0\% terhadap kinerja karyawan, sedangkan sisanya sebesar 44,0\% dipengaruhi faktor lain.

\section{d. Uji Hipotesis}

\section{Uji hipotesis Parsial (Uji t)}

Pengujian hipotesis dengan uji t digunakan untuk mengetahui hipotesis parsial mana yang diterima.

Hipotesis pertama: Terdapat pengaruh yang signifikan antara lingkungan kerja terhadap kinerja karyawan.

Tabel 9. Hasil Uji Hipotesis Lingkungan kerja Terhadap Kinerja Karyawan.

\begin{tabular}{|c|c|c|c|c|c|c|}
\hline \multirow{2}{*}{\multicolumn{2}{|c|}{ Model }} & \multicolumn{2}{|c|}{$\begin{array}{l}\text { Unstandardized } \\
\text { Coefficients }\end{array}$} & \multirow[t]{2}{*}{$\begin{array}{l}\text { Standardized } \\
\text { Coefficients }\end{array}$} & \multirow[b]{2}{*}{$t$} & \multirow[b]{2}{*}{ Sig. } \\
\hline & & $\mathrm{B}$ & Std. Error & & & \\
\hline & (Constant) & 21.614 & 3.869 & & 5.587 & .000 \\
\hline & Lingkungan kerja (X1) & .429 & .068 & .660 & 6.276 & .000 \\
\hline
\end{tabular}

a. Dependent Variable: Kinerja Karyawan $(\mathrm{Y})$

Berdasarkan hasil pengujian pada tabel di atas, diperoleh nilai $\mathrm{t}$ hitung $>\mathrm{t}$ tabel atau $(8,276>2,008)$, dengan demikian hipotesis pertama yang diajukan bahwa terdapat pengaruh yang signifikan atara lingkungan kerja terhadap kinerja karyawan diterima.

Tabel 10. Hasil Uji Hipotesis Kepemimpinan Terhadap Kinerja Karyawan.

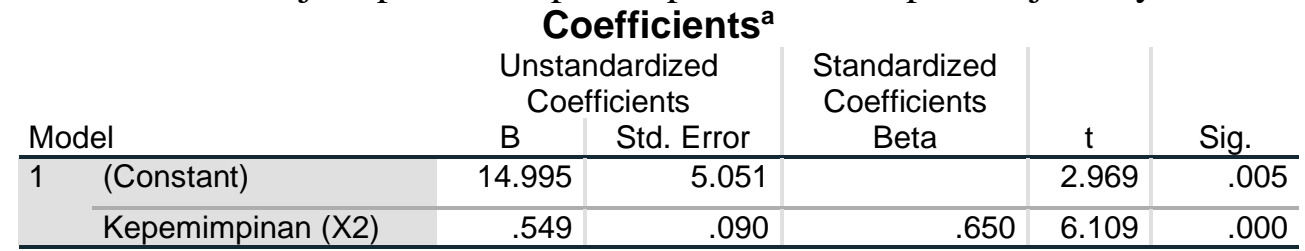

a. Dependent Variable: Kinerja Karyawan $(\mathrm{Y})$

Berdasarkan hasil pengujian pada tabel di atas, diperoleh nilai t hitung $>\mathrm{t}$ tabel atau $(6,109>2,008)$, dengan demikian hipotesis kedua yang diajukan bahwa terdapat pengaruh yang signifikan atara kepemimpinan terhadap kinerja karyawan diterima. 


\section{Uji Hipotesis Simultan (Uji F)}

Pengujian hipotesis dengan uji $\mathrm{F}$ digunakan untuk mengetahui hipotesis simultan yang mana yang diterima.

Hipotesis ketiga Terdapat pengaruh yang signifikan antara lingkungan kerja dan kepemimpinan terhadap kinerja karyawan.

Tabel 11. Hasil Uji Hipotesis Lingkungan kerja dan Kepemimpinan Terhadap Kinerja Karyawan.

\section{ANOVA $^{a}$}

\begin{tabular}{ll|r|r|r|c|c} 
Model & & Sum of Squares & df & Mean Square & F & Sig. \\
\hline \multirow{3}{*}{1} & Regression & 592.137 & 2 & 296.068 & 31.861 & $.000^{\mathrm{b}}$ \\
\cline { 2 - 7 } & Residual & 464.618 & 50 & 9.292 & & \\
\cline { 2 - 7 } & Total & 1056.755 & 52 & & & \\
\hline
\end{tabular}

Berdasarkan hasil pengujian pada tabel di atas, diperoleh nilai $\mathrm{F}$ hitung $>\mathrm{F}$ tabel atau $(31,861>2,790)$, dengan demikian hipotesis ketiga yang diajukan bahwa terdapat pengaruh yang signifikan atara lingkungan kerja dan kepemimpinan terhadap kinerja karyawan diterima.

\section{PEMBAHASAN HASIL PENELITIAN}

\section{Pengaruh Lingkungan kerja Terhadap Kinerja Karyawan}

Lingkungan kerja berpengaruh signifikan terhadap kinerja karyawan dengan korelasi sebesar 0,660 atau memiliki hubungan yang kuat dengan kontribusi pengaruh sebesar 43,6\%. Pengujian hipotesis diperoleh nilai $\mathrm{t}$ hitung $>\mathrm{t}$ tabel atau $(8,276>$ $2,008)$. Dengan demikian hipotesis pertama yang diajukan bahwa terdapat berpengaruh signifikan antara lingkungan kerja terhadap kinerja karyawan diterima.

\section{Pengaruh Kepemimpinan Terhadap Kinerja Karyawan}

Kepemimpinan berpengaruh signifikan terhadap kinerja karyawan dengan korelasi sebesar 0,650 atau memiliki hubungan yang kuat dengan kontribusi pengaruh sebesar $46,8 \%$. Pengujian hipotesis diperoleh nilai $t$ hitung $>\mathrm{t}$ tabel atau $(6,109>2,008)$. Dengan demikian hipotesis kedua yang diajukan bahwa terdapat berpengaruh signifikan antara kepemimpinan terhadap kinerja karyawan diterima.

\section{Pengaruh Lingkungan kerja dan Kepemimpinan Terhadap Kinerja Karyawan}

Lingkungan kerja dan kepemimpinan berpengaruh signifikan terhadap kinerja karyawan dengan diperoleh persamaan regresi $\mathrm{Y}=10,013+0,285 \mathrm{X} 1+0,325 \mathrm{X} 2$, nilai korelasi sebesar 0,749 atau memiliki hubungan yang kuat dengan kontribusi pengaruh sebesar 56,0\% sedangkan sisanya sebesar 44,0\% dipengaruhi faktor lain. Pengujian hipotesis diperoleh nilai $\mathrm{F}$ hitung $>\mathrm{F}$ tabel atau $(31,861>2,790)$. Dengan demikian hipotesis ketiga yang diajukan bahwa terdapat berpengaruh signifikan antara lingkungan kerja dan kepemimpinan terhadap kinerja karyawan diterima.

\section{KESIMPULAN DAN SARAN}

\section{Kesimpulan}

a. Lingkungan kerja berpengaruh signifikan terhadap kinerja karyawan dengan kontribusi pengaruh sebesar 43,6\%. Uji hipotesis diperoleh nilai t hitung $>t$ tabel atau $(8,276>2,008)$.

b. Kepemimpinan berpengaruh signifikan terhadap kinerja karyawan dengan kontribusi 
pengaruh sebesar 46,8\%. Uji hipotesis diperoleh nilai t hitung >t tabel atau $(6,109>$ 2,008).

c. Lingkungan kerja dan kepemimpinan berpengaruh signifikan terhadap kinerja karyawan dengan kontribusi pengaruh sebesar 56,0\% sedangkan sisanya sebesar $44,0 \%$ dipengaruhi faktor lain. Uji hipotesis diperoleh nilai $\mathrm{F}$ hitung $>\mathrm{F}$ tabel atau $(31,861>2,790)$.

\section{Saran}

a. Lingkungan kerja di PT. Uniform Indonesia sudah baik terutama dalam hal penerangan, maka peneliti dapat memberikan saran supaya perusahaan harus dapat mempertahankan dan meningkatkan lagi penerangan atau pencahayaan didalam lingkungan kerja.

b. Kepemimpinan di PT. Uniform Indonesia sudah baik terutama dalam hal laize faire, maka peneliti dapat memberikan saran kepada pimpinan perusahaan untuk tidak terlalu memberikan kebebasan kepada karyawannya dalam bekerja agar karyawan tetap memiliki tanggung jawab dalam pekerjaannya.

c. Kinerja karyawan di PT. Uniform Indonesia sudah baik terutama dalam hal kualitas kerja, maka peneliti dapat memberikan saran untuk perusahaan agar menjaga kualitas kerja karyawannya dan supaya perusahaan juga dapat terus meningkatkan kualitas kerja karyawannya agar dapat lebih baik lagi.

\section{DAFTAR PUSTAKA}

Akdon \& Riduan. 2010. Rumus dan Data Dalam Analisis Statistika. Cetakan 2. Alfabeta. Algifari. (2015). “Analisis Regresi untuk Bisnis dan Ekonomi”. Yogyakarta: BPFE.

Arikunto, Suharsimi (2014). "Prosedur Penelitian Suatu Pendekatan Praktek". Jakarta: Rineka Cipta.

Bangun, Wilson. 2012. Manajemen Sumber Daya Manusia. Erlangga. Jakarta. Farid dan Siswanto. 2011. Pengantar Manajemen. Jakarta: Bumi Aksara.

Edi Sutrisno (2016). Manajemen Sumber Daya Manusia. Jakarta: Prenadamedia Group.

Fandy Tjiptono (2017), Serivce Quality and Satisfiation. Jakarta: Edisi tiga. Andi.

Freddy Rangkuti (2016) Strategi Promosi Yang Kreatif, Edisi Pertama, Cetakan Pertama Jakarta: Gramedia Pustaka Utama

Freed Luthans (2016) Organizational Behavior, McGraw-Hill, New York.

Gerry Dessler (2016) Human Resources Management, Prenticehall, London: International Inc.

Ghozali, Imam. 2012. Aplkasi Analisis Multivariate dengan Program IBM SPSS 20. Semarang: Badan Penerbit - Universitas Diponegoro.

Griffin R.W., \& Ronald, J.E. (2003). Dasar-Dasar Pemasaran. Jakarta: Raja Grafindo Handoko (2016) Manajemen Personalia dan Sumberdaya Manusia. Yogyakarta: BPFE. Hasibuan (2016) "Manajemen Sumber Daya Manusia”. Haji Masagung. Jakarta. Henry Simamora (2005), Manajemen Sumber Daya Manusia, STIE YKPN Bandung. Hurriyati, Ratih. 2015. Bauran Pemasaran dan Loyalitas Konsumen. Alfabeta, Bandung. Imam Ghozali (2017). "Aplikasi Analisis Multivariate Dengan Program SPSS”. Edisi Kelima. Semarang: Badan Penerbit Undip.

Istijanto (2014) “Riset Sumber Daya Manusia”. Jakarta: PT. Gramedia Pustaka Kaso, N., Mariani, M., Ilham, D., Firman, F., Aswar, N., \& Iksan, M. (2021). The Principal's Leadership: How to Improve the Quality of Teaching and Learning Process in State Junior High School of Luwu. Jurnal Ad'ministrare, 8(1), 49-58. https://doi.org/10.26858/ja.v8i1.19126 
Malayu S.P., Hasibuan. 2011. Manajemen Sumber Daya Manusia. Bumi Aksara. Jakarta.

Mathis, Robert L. dan John H. Jackson. 2012. Manajemen Sumber Daya Manusia. Edisi Pertama. Salemba Empat.

R. Terry, George. 2010. Dasar-Dasar Manajemen. Cetakan Kesebelas. Jakarta: PT Bumi Aksara.

Samsudin, Sadili. 2009. Manajemen Sumber Daya Manusia. Bandung: CV Pustaka.

Sudarso, A. P. (2017). Analisis Pengaruh Gaya Kepemimpinan Dan Insentif Terhadap Kinerja Karyawan Pada Yayasan Pendidikan Mulia Buana. JENIUS (Jurnal Ilmiah Manajemen Sumber Daya Manusia), 1(1).

Sugiyono. 2010. Metode Penelitian Pendidikan Pendekatan Kuantitatif, Kualitatif, dan $R \& D$. bandung: Alfabeta.

Suherman, H. (2018). Pengaruh Gaya Kepemimpinan Dan Disiplin Kerja Terhadap Kinerja Karyawan PT. Selaras Karya Raya Jakarta. JENIUS (Jurnal Ilmiah Manajemen Sumber Daya Manusia), 2(1).

Sunarsi, D. (2019). Penerapan MSDM Strategis Dalam Upaya Meningkatkan Kemampuan Organisasi dalam menyongsong Revolusi 4.0. Jurnal Ilmiah MEA (Manajemen, Ekonomi, \& Akuntansi), 3(1), 221-233.

Sunyoto, Danang. 2012. Dasar-Dasar Manajemen Sumber Daya Manusia. Yogyakarta: CAPS.

Tua E.H, Marohot. 2012. Manajemen Sumber Daya Manusia. Bandung. PT. Remaja Rosdakarya.

Veitzal Rivai, Deddy Mulyadi. 2010. Kepemimpinan Perilaku Organisasi. Jakarta: Rajawali Pers.

Wibowo. 2012. Manajemen Kinerja. Edisi ke 3. Jakarta: Rajawali Pers. 